\title{
Agent Based System for improved Control and Monitoring of a Solar Driven DC Microgrid
}

\author{
Diana Rwegasira $^{12}$, Nerey Mvungi ${ }^{2}$, Hannu Tenhunen ${ }^{1}$ \\ ${ }^{1}$ KTH Royal Institute of Technology in Stockholm, P.O.BOX 229, 16440 (SWEDEN) \\ ${ }^{2}$ University of Dar es Salaam, P.O.BOX 5555, 14113 (TANZANIA) \\ dianasr@kth.se,nhmvungi@udsm.ac.tz, hannu@kth.se.
}

\begin{abstract}
Control and monitoring processes in the electric field are fundamental aspects in smart grid. Different attributes, systems and mechanisms are required in handling activities from transmission, distribution and consumer side of the electrical network based on advanced technologies. In Tanzania, there still exists manual operations on distribution side and very little on the transmission side. Agent based distributed system has been seen to work successfully which involves the use of artificial intelligence and autonomous actions during the operations and controlling activities. Therefore, in this manner, the generated model based on REPAST simulation tool for solar driven DC microgrid will be achieved to show features of control and monitoring the grid including load shedding technique and demand responses based on pricing. Furthermore, the design of the prototype based on the stated features will be implemented. The advantages and impact of the demonstration can be deployed and used in any community for the application of any renewable energy systems.
\end{abstract}

Keywords: Agent based systems, demand response, microgrid, and smart grid

\section{INTRODUCTION}

Electricity is a great invention for human life. To achieve the growth of the countries' economy, a safe and reliable technology in the provision of smart electricity is one of the factors which have to be considered. Smart grid is one of the latest technologies in the provision of automatic electric network from generation to the end users. It includes features such as self-healing, fault tolerance and detections, demand side managements and automatic load shedding. According to [1], the smart grid is an electric network that can intelligently and smartly integrate the actions and users connected to it (generators, consumers, transmitters, distributors and those that do both) so as to efficiently deliver sustainable, economic and secure electricity supplies. Many countries have seen and started to benefit from smart grid and applications from the grid infrastructure, healthy and agricultural sectors as well as distributed supercomputing. The work by [2] stated that, smart grid deployments must include not only technology, market and commercial considerations, environmental impact, regulatory framework, standardization usage, Information and Communication Technology (ICT) but also societal requirements and governmental edicts. These characteristics of smart grid have made the customer side manageable and controllable, hence reduce the operational costs.

In Tanzania less implementation of smart grid has been done in the control and monitoring of the electric systems. The
Tanzania Electric Supply Company (TANESCO) which is the sole supply company of the electricity in Tanzania, the transmission side is the part which has been implemented in the process of monitoring and controlling with smart grid and lesser extent to the primary distribution side of the grid system. There is still a need for the automation process in the control of electric power so as to increase efficiency in all aspects of the electric power system, optimize cost to consumers and reduce human interventions and errors. Also, the use of renewable energies such as solar and wind are more valuable in the utilization and provision of electricity in places with no access to the national grid. When the smart network system has been integrated with renewable energies as a source of power, this is referred to as smart microgrid. According to [3], microgrid systems are capable of rapidly detecting, controlling, managing, analyzing and responding to various perturbations in the network by integrating advanced control methods such as agent based systems.

The control and management of distributed energy systems using agent based systems in smart grid have been seen to work effectively in the provision of autonomous actions. According to [4], "An agent is a computer system or device that is situated in some environment and is capable of taking autonomous action in this environment in order to meet its design objectives". The system which has more than one agent working together is referred to as multi agent system. The study by [5] discussed that, agent based system can be applied in the management of distributed energy systems including demand side management, storage and generation. Other sectors by which multi agent systems can be applied are ehealthy, transportations and infrastructure.

The applications of agent based system during normal and emergency situations have resulted into proper utilization of smart microgrid monitoring and controlling. Recently, researchers introduced multi-agent systems which replaced supervisory control and data acquisition system (SCADA) in monitoring and control of microgrid areas, [6]. This is due to its applicability in both centralized and decentralized manner. The research done by [7] and [6] showed that, current trends on monitoring and controlling of operations in electric power systems are moving towards the use of an automated agent systems. The advantages of multi agent systems are the results of several advantages such as modularity, autonomy, scalability and re-usability of the systems. Several applications which have been worked successfully based on the use of agent based systems are: (i) controlling of generators in the 
microgrid system at military camp settings done by [8] and (ii) scheduling activities in electric systems done by [9].

This work is focusing on the controlling and monitoring of a solar driven DC microgrid. The aim of the work is the use of agent based systems for developing the model and simulating the results before implementations on the real system. The approach is to run an optimal algorithm which combines the automatic load shedding and selling extra power to an individuals upon having it. This will include modeling of the solar agent, storage agent and load agent to acquire the features of solar panel, storage and residential loads. The simulated results will be extended through designing of the prototype and demonstrating on how it can be deployed into the real system. The prototype will be proposed as an improved platform to deploy it in the community to control and monitor the DC microgrid.

The Main Objective is:

To improve on controlling and monitoring of DC Microgrid using agent based system with load shedding technique in off grid communities.

The Specific Objectives are:

i. To analyze existing systems on controlling and monitoring of DC microgrid (specifically on solar systems) using agent based systems in smart grid.

ii. To develop an algorithm for solar DC microgrid.

iii. To propose a platform for the implementation and application on the DC microgrid.

The Research Questions are:

i. What are the challenges facing the implementations of agent based distributed control on solar driven DC in smart grid?

ii. How does the algorithm developed for DC microgrid lead to the effect in smart system?

iii. How does the designed platform for DC microgrid lead to the effect in smart system?

\section{CDE PRACTICE TOWARDS EXPLORING THE RESEARCH} PROBLEM

Challenge Driven Education (CDE) is a methodology for creating skills to students towards solving societal problems [10]. It involves the design thinking approach, stakeholders and students to obtain the challenges.

The CDE approach is used around the following steps:

i. The external stakeholders to define the real-life problems and challenges in a specified sector, for this is electricity.

ii. Students to be assigned to address those challenges in accordance with their skills and expertise. This can be done with the help of the instructors until the best solutions are proposed.

iii. Students to work in team to propose solutions to the defined problems.

CDE is involving in the iGrid project which focuses on Capacity Development and Enhancement in Tanzania research training program to design and develop human technical and scientific capacity to implement an automation on monitoring, evaluation, analysis, control and management of electrical power system (smart grid) in order to improve delivery efficiency and to optimize operational costs in the electrical power system in Tanzania within the area of Microgrid.

Several meetings were done with stakeholders for the identification of the challenges to be solved. The first meeting was held in 11th January-2016 with the management and technical people from REA which is an autonomous body under the Ministry of Energy and Minerals of the United Republic of Tanzania dealing with promoting and facilitating improvements on access to modern energy services in rural areas of mainland Tanzania. The meeting was focusing on identifying potential areas in Tanzania in which iGrid project could offer as a solution and several sites in NgorongoroArusha and Kisarawe-Pwani where identified.

Moreover, another meeting was on 27th September-2016 with stakeholders who participated in the project [11] piloted at Kisiju, Pwani. This project involved in photovoltaic based minigrid for electrification of remote areas in Tanzania. The output of this meeting resulted in a number of challenges towards operations and maintenance of the microgrid system. Basically, this is the site we are using in the iGrid project to solve the community problem.

Furthermore, to understand the extent of smart grid implementation in Tanzania, several meetings with stakeholders were done at TANESCO, Head Quarters and SCADA at Mikocheni in March 2016. These provided the clear insight of the stages which have been done towards achieving smart grid systems in Tanzania. Several achievements include automatic meter reading to read data from customers with high power consumptions, remote configurations of the new sites and automatic detection of faults in the distribution sites.

\section{RELATED WORK}

Many researchers have worked with DC microgrid control and monitoring on achieving several experiments based on smart grid systems. In most cases, the focus was on how to optimize the power usage, to minimize the cost, to monitor and control the loads at the consumer side. The research done by [12], proposed a model for DC microgrid using PV as source of power that can later be integrated to the main electric grid. The focus of the work was on sharing of extra power among the consumers. Also, the author used MATLAB tool to simulate the results. The work by [13], designed a multi agent system with secure critical loads using PV systems as a source of electric power. The work focused on external fault detections, secure loads and resynchronization of microgrid to the main grid after fault clearance.

Moreover, the research done by [14] used a micro-CHP (Combined Heat and Power) to generate DC power for microgrid. The model developed was based on load shifting technique. The load/house is equipped with smart meter and controllable devices. The work addressed the solution using agent based systems as well as using REPAST simphony simulation tool [15]. Also in 2014, the research by [16] and [17] developed a stochastic model predictive control for optimal economic operation in a residential DC microgrid. The authors used PV arrays for power sources, battery stack and 
fuel stack to optimize the power flow. They also used the linear programming approach to model their work.

\section{METHODOLOGY}

\section{A. Study Design and Materials}

\section{Establishing Challenges}

The study will start by adopt the Literature review approach. In this method, relevant literatures on Journals, research papers, books, companies and laboratories involved in smart grid that covers the extent of the study will be done. This will focus on different aspects which form a core control and monitoring in smart grid in DC Microgrid from generation to distribution side. These include: DCDC conversions, Solar panel storages and technologies, Smart grid technologies, challenges and implementations, Agent based distributed algorithm and simulation tools for DC smart microgrid, Agent based systems applications and Business models issues and Innovation process on smart grid.

\section{Project Materials and Requirements}

The requirements/materials and its specification will be established in response to needs as the research work developed. This will include equipment such as programmable chips (Arduino and Raspberry Pi), smart sensors and actuators, smart DC devices, energy storage, load, grid control units, server, simulation software, computer, etc. The detailed requirements will be determined after conducting the survey from sites, companies and laboratories which deal with control and monitoring in microgrid and smart grid such as Mikocheni, TANESCO and Stockholm smart grid control.

\section{B. System Design and Implementation}

The approach on accomplish this will base on the experimental research method. The selection of the method is due to the experimental setup as seen in Figure 1. The design will follow the following sequence:

\section{Algorithm}

Construction of the optimal algorithm which has to run with different parameters and variables such as solar, storage and load profiling, number of houses, sun shine, power consumption and production, etc. and include features of "demand response in pricing" to see the effect of the model generated. These will focus on the challenge based on automatic Load shedding technique to categories critical and non-critical loads in the community.

\section{Design}

In this section, based on the algorithm in (i) the experiment in Fig. 1 will be design with the features mentioned in (i) using "agents". These will include solar agent, storage agents and load agents which will be in the distributed manner. The load agent will also have a capability to own its own solar and storage which will act as internal agent for production and consumption. The designed experiment has to include features of smart grid such as adaptability, sociability, scalability and proactive.

\section{Simulation}

The use of Agent based simulation tool REPAST Simpony [15] will be used. This is the tool which runs in Java and includes features of visualization (2D), step by step running and customization of the requirements. The choice of this tool is due to the fact that it is recently developed platform and its functionality has been proven to work successfully when using agents.

\section{Development}

This phase will involve the use of the selected equipment to develop the 1st prototype based on the model generated in (iii). The focus of this phase is to obtain the prototype with the control capabilities and optimization characteristics. This will be done through different functionalities of the system such as (1) maintaining production while increase consumptions, (2) Increase the loads/houses which consumes only, etc.

\section{Testing}

The prototype will be tested in the selected site and refined before the release of the final prototype.

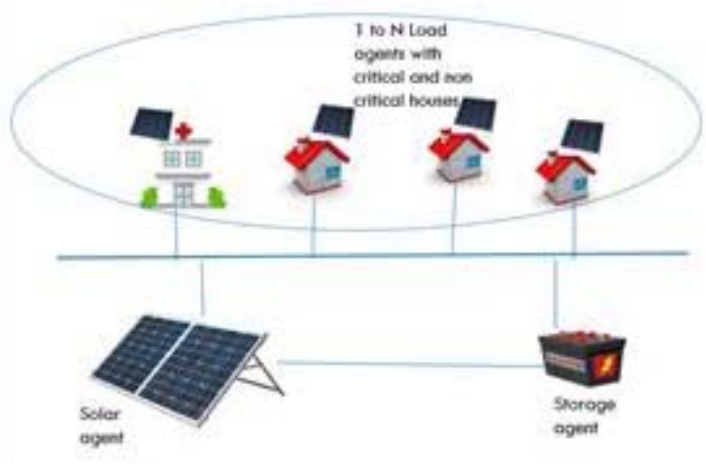

Fig. 1. Experimental setup of DC Microgrid

\section{Study Area}

The selection of the pilot area will be done upon visiting different potential site related to the project. The selection will focus on the following criteria: the community with no source of power or, the community with the provision of solar power but with no smart grid intervention or, the system with challenges such as fault detection, automatic load shedding technique, self-healing system in electrical network.

With respect to these features mentioned above, the selected site is Kisiju Pwani [11] which has the provision of solar as a power source and saving approximately 70 houses, small markets, mosque and street lights. The system has not yet included any features of smart grid technology.

\section{Data Analysis}

Based on the experimental approach used, the model generated will be analyzed with different parameter and variables, then, validated and obtain results to be discussed with different scenarios such as production and consumption ratio, etc. Also, It will focus on the improvement in the control and optimization of the whole system with agent based system upon adding other loads or changing of the environments. Features such as response time and demand response will be verified upon implementation of the prototype. Data analysis tool such as excel spreadsheet will be used for analysis and demonstrate the results.

Table I clearly shows the schedule of the activities up to the completion of the research.

\section{CURRENT STATUS}

The use of the REPAST simulation tool has added much value to this project. The modeling part based on an agentbased distributed system with several features have been developed. The tool makes use of JAVA programming 
language to develop agents and simulate in a step running model. The results in [16], the work mainly focused on the solar driven DC microgrid targeting the static loads. In this case, the critical and non-critical loads were able to be distinguished and the results were able to perform the load shedding technique. The model was tested with 3 houses.

Another work was in [17] whereby this was the extension of the previous work. The idea was to use dynamic loads and provide a framework with load shedding techniques as well as demand response scheme. Two ways of simulations based on PV systems and the solar panel where the focus of this work. The model also described the algorithm for the solar panel, storage battery and loads and then describe the agents' collaboration on the framework. Furthermore, the modeling of the system with demand response based on pricing issues was developed and the simulation was demonstrated with three houses as seen in Fig. 2 showing the parameters whereby the user can insert before simulating the microgrid.

Consumer: Critical Load valuer:
300
Default Random Seed:
850500914
Main consumer: Max consumption:
25,000
Main consumer: Min consumption:
15,000
Normal consumer: Max consumption:
6,000
Normal consumer: Min consumption:
2,000
Number of consumers:
3
Start date(DD/MM/YrYY):
$1 / 1 / 2017$
Start time(HH:MM):
$06: 00$
Supplier solar battery capacity(Amph):
40,000
Supplier solar battery threshold:
50
Supplier solar battery voltage(V):
48
Supplier: Maximum price(Per Unit):
10,000
Supplier: Minimum price(Per Unit):
500
Supplier: Normal price(Per Unit):
1,000
Supplier: Number of panels:
86,000
Supplier: Panel voltage:
24
Supplier: Price increment (T):
300

Fig. 2. Parameters for simulation

Also, the model provides the individual load to sell/buy electric power into the grid based on its preferences. Fig. 3 shows the behavior of power generated from sunrise to sunset. The maximum peak power generated is when there is a maximum sunshine. The characteristics of the battery is also seen in Fig.4 where the battery discharges up to the defined $\mathrm{SoC}$ of $30 \%$

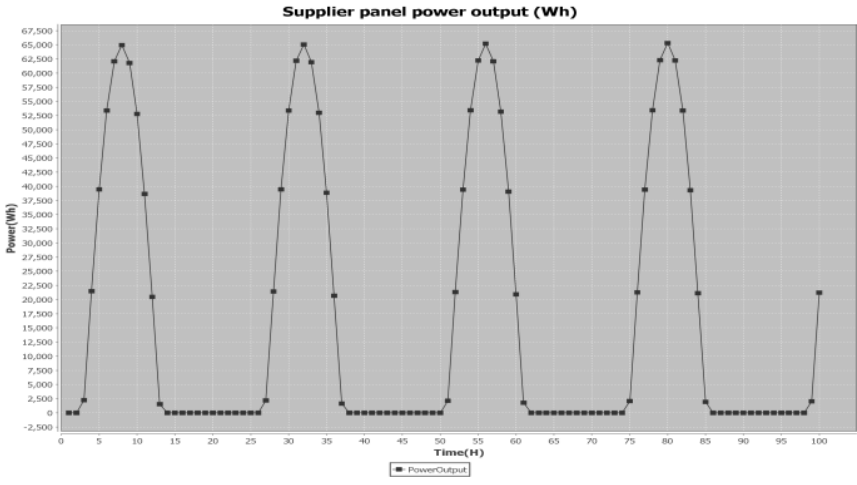

Fig. 3. Solar panel power against time

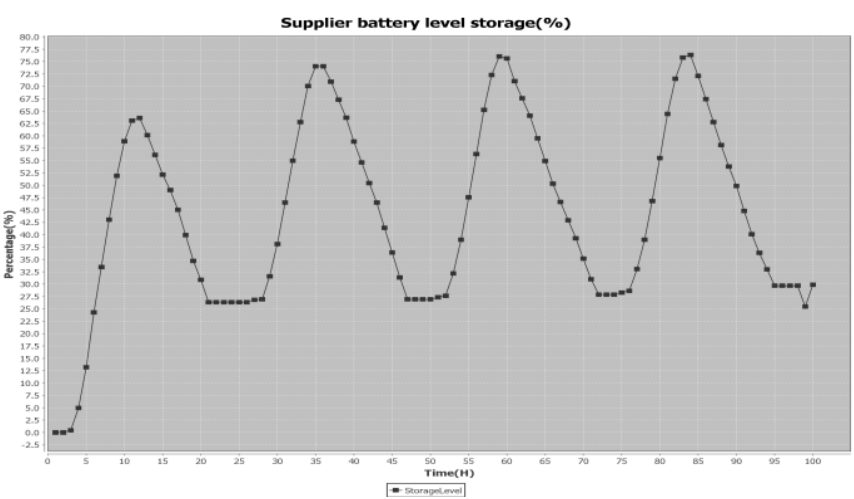

Figure 4. Behavior of the battery on charging and discharging

Fig. 5 describes the simulation on the solar panel based on the power generated and supplied to the storage and loads while Fig. 6 shows the extra power obtained when individual load supply to the solar panel.

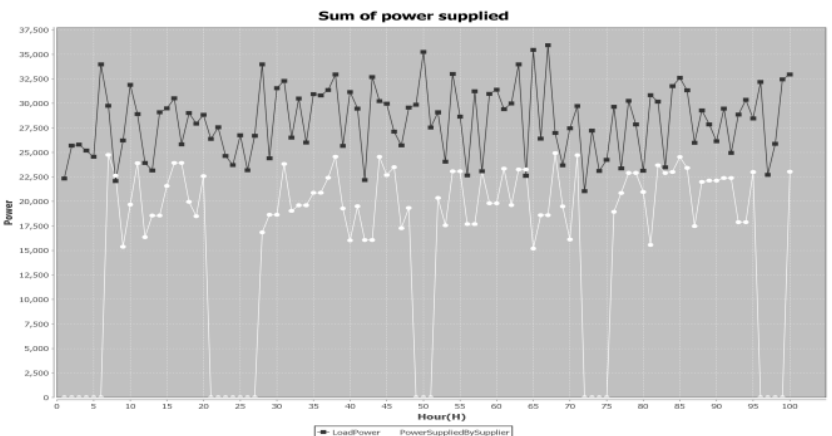

Fig. 5. Power supplied and generated

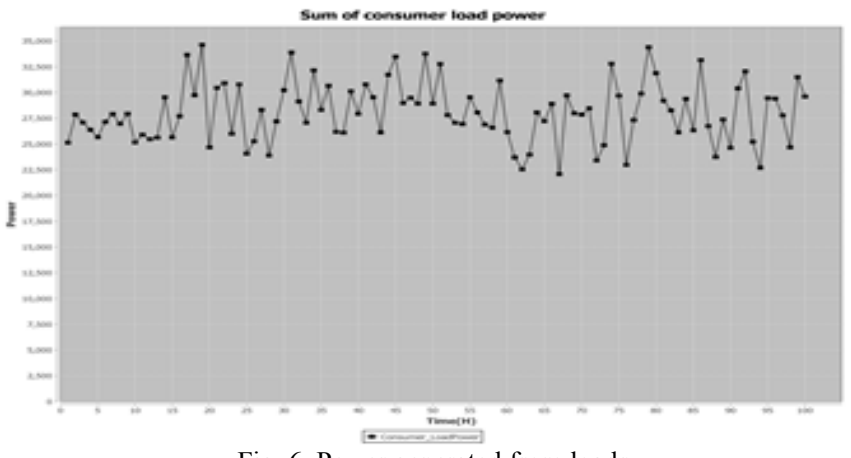

Fig. 6. Power generated from loads 
TABLE I. SCEHDULE OF ACTIVITIES

\begin{tabular}{|c|c|c|c|c|c|c|c|c|}
\hline \multirow{3}{*}{ Activities in Tanzania \& Sweden } & \multicolumn{8}{|c|}{ Time Schedule in Years } \\
\hline & \multicolumn{2}{|c|}{2016} & \multicolumn{2}{|c|}{2017} & \multicolumn{2}{|c|}{2018} & \multicolumn{2}{|c|}{2019} \\
\hline & Jan-Jun & Jul-Dec & $\begin{array}{l}\text { Jan- } \\
\text { Jun }\end{array}$ & Jul-Dec & $\begin{array}{l}\text { Jan- } \\
\text { Jun }\end{array}$ & Jul-Dec & Jan-Jun & Jul-Dec \\
\hline $\begin{array}{l}\text {-Literature review, site surveys and laboratory visits } \\
\text {-Proposal formulating and Presentation } \\
\text {-Attending courses relevant to my research }\end{array}$ & & & & & & & & \\
\hline $\begin{array}{l}\text {-1st Prototype released and testing } \\
\text {-Attending courses relevant to my research }\end{array}$ & & & & & & & & \\
\hline $\begin{array}{l}\text {-Algorithm design and simulation developments with several } \\
\text { experiments (Journal and conference papers) }\end{array}$ & & & & & & & & \\
\hline -2nd Prototype released and testing & & & & & & & & \\
\hline
\end{tabular}

\section{CONCLUSION}

The ongoing activities are: (i) modelling of the system with respect to demand response based on pricing issues, whereby the system will be able to control the price based on the consumption and availability of power in the grid. Moreover, the individual load will be able to sell/buy power into the grid based on its preferences, (ii) development of the prototype based on the features stated earlier with devices such as arduino, raspberry pi and smart sensors.

\section{ACKNOWLEDGEMENT}

This work is supported by the Swedish government through the SIDA project.

\section{REFERENCES}

[1] A. Zaballos, A. Vallejo, and J. M. Selga, "Heterogeneous communication architecture for the smart grid," IEEE Netw., vol. 25 , no. 5 , pp. $30-37,2011$.

[2] J. Joy, E. a Jasmin, and V. R. John, "Challenges of Smart Grid," Int. J. Adv. Res. Electr. Electron. Instrum. Eng., vol. 2, no. 3, pp. 976-981, 2013.

[3] S. Kihwele and A. L. Kyaruzi, "Effect of Poor Designing of Distribution System Case Study Tanzania Electric Supply Company Network," in 2004 International Conference on Power System TEchnology- POWERCON, 2004, no. November, pp. 1298-1302.

[4] F. Davoodi Samirmi, W. H. Tang, and Q. H. Wu, "Implementation of Gaia methodology for multi-agent based transformer condition monitoring," in IEEE PES Innovative Smart Grid Technologies Conference Europe, 2012, pp. 1-8.

[5] Z. Jiang, "Agent-Based Control Framework for Distributed Energy Resources Microgrids," in 2006 IEEE/WIC/ACM International Conference on Intelligent Agent Technology, 2006, pp. 646-652.

[6] A. Kantamneni, L. E. Brown, G. Parker, and W. W. Weaver, "Survey of multi-agent systems for microgrid control," Eng. Appl. Artif. Intell., vol. 45, pp. 192-203, 2015.

[7] K. Manickavasagam et al., "Control of Distributed
Generator and Smart Grid using Multi-agent System," in 1st International Conference on Electrical Energy Systems, ICEES, 2011, pp. 212-217.

[8] M. Pipattanasomporn, H. Feroze, and S. Rahman, "Multiagent systems in a distributed smart grid: Design and implementation," IEEE/PES Power Syst. Conf. Expo. 2009. PSCE '09., pp. 1-8, 2009.

[9] P. G. Ansola, A. G. Higuera, F. J. Otamendi, and J. De Morenas, "Agent-Based Distributed Control for Improving Complex Resource Scheduling: Application to Airport Ground Handling Operations," IEEE Syst. J., vol. 8, no. 4, pp. 1145-1157, 2014.

[10] M. Magnell and A.-K. Högfeldt, Guide to challenge driven education ECE Teaching and Learning in Higher Education no 1, no. 1. 2015.

[11] B. M. M. Mwinyiwiwa, R. T. Kivaisi, and C. Msoka, "Photovoltaic based Mini-Grid for Electrification of Remote Areas of Tanzania : The case of Kisiju-Pwani Village," Dar es Salaam, Tanzania, 2013.

[12] Q. Syeda, A. Hassan, and A. Nauman, "SMART DC MICROGRIDS : communities," IEEE, 2014.

[13] M. Pipattanasomporn, H. Feroze, and S. Rahman, "Securing critical loads in a PV-based microgrid with a multi-agent system," Renew. Energy, vol. 39, no. 1, pp. 166-174, 2012.

[14] M. Tasdighi, H. Ghasemi, and A. Rahimi-Kian, "Residential Microgrid Scheduling Based on Smart Meters Data and Temperature Dependent Thermal Load Modeling," IEEE Trans. Smart Grid, vol. Early Acce, no. 1, pp. 1-9, 2013.

[15] M. Bragen, N. Collier, J. T. Murphy, J. Ozik, and E. Tatara, "http://repast.sourceforge.net/," 2012. [Online]. Available: http://repast.sourceforge.net/.

[16] M. Gulin, M. Vasak, and T. Pavlovic, "Model identification of a photovoltaic system for a DC microgrid simulation," 16th Int. Power Electron. Motion Control Conf. Expo. PEMC 2014, pp. 413-418, 2014.

[17] M. Gulin, J. Matusko, and M. Vasak, "Stochastic model predictive control for optimal economic operation of a residential DC microgrid," IEEE Int. Conf. Ind. Technol., pp. 505-510, 2015. 